\section{Penelitian Guru untuk Mempersiapkan Generasi Z di Indonesia}

\author{
Sparisoma Viridi ${ }^{1}$, Jam'ah Halid ${ }^{2}$, Tati Kristianti ${ }^{3}$, \\ Reza Setiawan ${ }^{4}$ \\ ${ }^{1}$ Prodi Fisika, FMIPA, Institut Teknologi Bandung \\ Jalan Ganesha 10, Bandung 40132, Indonesia \\ ${ }^{2}$ Lembaga Pengembangan Pendidikan Salman ITB \\ Jalan Ganesha 7, Bandung 40132, Indonesia \\ ${ }^{3}$ OpenLab Salman ITB \\ Jalan Ganesha 7, Bandung 40132, Indonesia \\ SEAMEO QITEP in Science \\ Jalan Diponegoro 12, Bandung 40115, Indonesia \\ 1dudung@gmail.com, 2 jhalidwae@gmail.com, \\ ${ }^{3}$ kristianti007@yahoo.com, ${ }^{4}$ rezaitb@gmail.com

\section{DOI: 10.17605/OSF.IO/9TRA7}

Dewasa ini informasi tidak lagi dapat dibendung, yang selain membanjiri kita sehingga membingungkan juga dapat menyebabkan kerisauan (Bawden \& Robinson, 2009). Untuk mengatasinya diperlukan strategi, yang salah satunya adalah menarik diri dari akses informasi dan menjaga sumber informasi menjadi minimum (Savolainen, 2007). Pada sisi lain dengan semakin banyaknya pengetahuan (dan inovasi) baru yang dibuat dan dapat dengan mudah diakses, isi menjadi bukan lagi menjadi yang utama melainkan bagaimana mengetahui informasi menjadi lebih penting bahkan dari informasi itu sendiri (Rotherham \& Willingham, 2010). Dalam era seperti inilah generasi $Z$ dilahirkan dan bertumbuh.

Generasi Z, umumnya merujuk pada generasi yang lahir pada atau setelah tahun 1990 yang telah terbiasa dengan teknologi internet sejak usia dini (Geck, 2006), berbeda dengan generasi sebelumnya, generasi ini berhitung dengan keamanan finansial, lebih kompetitif, menginginkan kebebasan, bekerja multitasking, lebih bersifat wirausaha, ingin berkomunikasi dengan tatap muka, murni generasi digital, dan ingin dilayani (Patel, 2017). Generasi inilah yang menjadi perserta ajar dari guru-guru pada masa ini. Pembelajaran yang perpusat guru tidak lagi cocok pada generasi ini sehingga perlu berubah ke pendekatan yang lebih berpusat siswa, terutama pada populasi siswa yang amat beragam kemampuannya (Brown, 2003). Agar siap untuk mengajar generasi ini guru (dan juga siswa) perlu berubah, yang sudah pasti tidak mudah bahkan di Finlandia sendiri (Eriksson et al., 2017), suatu negara dengan sistem pendidikan terbaik saat ini (Hart, 2017).

Penelitian merupakan salah satu cara agar guru dapat berubah dan bila diterapkan dengan tepat siswa-siswa dengan karakter generasi $Z$ dapat pula terakomodasi. Untuk itu terdapat beberapa hal yang perlu dipersiapkan untuk mendorong penelitian guru, yang salah satunya adalah insentif penelitian (Cohran-Smith \&
Lytle, 1990), yang dalam hal ini telah dirintis oleh SEAMEO QITEP in Science sejak tahun 2015 dalam bentukk SEAQIS Research Grant (Khumaidi, 2017). Selain itu, penelitian guru perlu didukung karena akan mengkomodasi refleksi guru, yang penting untuk pembaruan edukasional dan perkembangan profesionalisme guru (Crookes, 1993).

Alternatif metoda pembelajaran yang dapat digunakan adalah Project-Based Learning (PBL) yang membuat siswa tumbuh kemampuannya lewat inkuiri dan juga mampu bekerja kolaboratif untuk meneliti serta pembuat proyek yang menggambarkan tingkat pengetahuan mereka (Bell, 2010).

Karya dari tiga orang guru yang mendapatkan SEAQIS Research Grant pada tahun 2017 akan diulas secara singkat di sini. Mereka-mereka itu adalah Cece Sutia dari SMAN 1 Parongpong, Lembang, Jawa Barat (Sutia, 2017), Ernawati Setyo Nugraheni dari SDN Kemiri, Sidoarjo, Jawa Timur (Nugraheni, 2017), dan Priya Santosa dari SMAN 1 Dolopo, Madiun, Jawa Timur (Santosa, 2017). Semangat dan kegigihan mereka dalam mengembangkan penelitian untuk membantu pembelajaran siswa patut mendapatkan acungan jempol.

Sumber air yang layak minum masih merupakan permasalahan di Indonesia pada beberapa daerah (Patunru, 2015), yang untuk mengatasinya memerlukan kerangka regulasi yang tepat untuk sektor air ini (Irianti et al., 2016). Dan bila terjadi bencana banjir, salah satu permasalahannya adalah air bersih. Saat banjir, air berlimpah tetapi tidak layak konsumsi karena sumber yang ada tercemari (McGuigan et al., 1999). Dengan menggunakan model pembelajaran Engineering Design Process (EDP) siswa diperkenalkan pada sistem penyaringan air sederhana, belum sampai layak minum dengan indikator cukup kejernihannya. Terdapat dua kelompok dengan perlakukan berbeda, yaitu yang alat dan bahan telah dibatasi dan yang dibebaskan. Teramati bahwa kelompok kedua memiliki tingkat kreativitas lebih dibandingkan kelompok yang pertama (Sutia, 2017). Setelah ini para siswa mungkin dapat diajarkan indikator lain yang membuat air layak minum sehingga saat terjadi permasalahan, mereka dapat banyak berkontribusi.

Penghantaran kalor merupakan salah satu konsep fisika yang menarik, yang selain diajarkan secara konvensional juga diajarkan dengan berbasiskan web (Tas, 2011) dan melalui eksperimen jarak jauh yang dapat dikendalikan dan hasilnya teramati (da Silva, 2014). Dengan melihat kearifan lokal konsep fisika tersebut dieksplorasi dalam kegiatan keseharian pembatik di daerah Sidoarjo, daerah sekitar lokasi siswa bersekolah. Ketiga bentuk penghantaran kalor seperti konduksi, konveksi, dan radiasi dapat ditemukan dalam aktivitas-aktivitas seperti memanasnya keseluruhan wadah untuk melumerkan lilin dan merebus kain, bergolaknya air dan 
cairan lilin, serta panasnya api yang terasa dan proses penjemuran kain batik. Siswa juga diminta melihat korelasi antara tingkat kekentalan lilin sebagai fungsi panasnya wadah dengan jumlah ceceran lilin, yang mengajarkan statistik secara sederhana (Nugraheni, 2017). Hal terakhir ini menarik untuk ditelaah lebih lanjut.

Proses fotosintesis yang terjadi pada tumbuhan merupakan suatu konsep yang menarik untuk dikaji karena siswa SD dapat beranggapan bahwa tanaman tidak bernafas atau bernafas seperti orang dan tumbuhan, serta selalu membutuhkan $\mathrm{CO}_{2}$ dan menghasilkan $\mathrm{O}_{2}$ baik siang maupun malam (Canal, 1999), sementara siswa SMP beranggapan pada pada malam hari tanaman bernafas dan pada siang hari kebalikannya yang dikaitkan dengan gas yang dibutuhkan dan yang dihasilkan (Stavy et al., 1987). Kesulitan dalam mengajarkan fotosintesis dapat dimengerti mengingat diperlukan pemahaman berbagai bidang, tidak hanya biologi melainkan juga kimia (Tekkaya, 2001), yang meliputi proses pelepasan oksigen, sumber oksigen, analisis dan sintesis senyawa kimia dengan bantuan energi cahaya, fungsi cahaya dalam proses, serta fungsi klorofil dan koloropastid (Eisen \& Stavy, 1992). Dengan berawal menggunakan corong kaca sebagaimana petunjuk eksperimen untuk mengamati proses fotosintesis, sebuah ruangan untuk membatasai cahaya dari luar dan di dalamnya diberikan sumber cahaya yang dapat dipilh warnanya, telah dirancang untuk mengamati pengaruh dari panjang gelombang terhadap tingkat aktivitas proses tersebut (Santosa, 2017). Sistem yang dirancang masih disederhanakan lagi sehingga siswa dapat mencobanya sendiri di rumah, tanpa kuatir dapat mengalami kecelakaan terkait dengan lampu neon yang digunakan dan arus bolak-balik $220 \mathrm{~V}$ sebagai sumbernya.

Bila terdapat banyak guru yang dapat dan berminat melakukan penelitian sehingga proses pembelajaran dapat menjadi lebih baik, maka kita dapat optimis bahwa generasi $Z$ akan siap dalam menghadapi kehidupannya di masa depan. Dan sebaiknya regulasi mengakomodasi dan memfasilitasi hal ini, serta memanfaatkan pula hasil-hasil telaah guru-guru sebagai suatu kebijakan yang konstruktif untuk membangun sistem pendidikan yang lebih baik di Indonesia. Selama ini kebijakan umumnya bersifat top-down. Ada baiknya mulai bersifat bottom-up dengan mengambil manfaat dari hasil penelitian guru-guru. Dengan demikian tidak akan ada lagi kebijakan yang salah sasaran atau tidak dapat dilaksanakan karena sudah pernah dicoba oleh para ujung tombak pengajaran, yaitu guru-guru sendiri.

Bell S 2010 Clearing House J. Educ. Strategies Issues Ideas 83 39.

Bawden D, Robinson L 2009 J. Inf. Sci. 35180.

Brown KL 2003 Educ. 12449.

Canal P 1999 Int. J. Sci. Educ. 21363.

Cohran-Smith M, Lytle S L 1990 Educ. Res. 192.

Crookes G 1991 Appl. Linguist. 14130. da Silva JB, Rochadel W, Simão JPS, da Silva Fidalgo 2014 AV IEEE-RITA 928.

Eisen Y, Stavy R 1992 Am. Biol. Teach. 54339.

Eriksson N, Romar J-E, Dyson B 2017 Int. J. Action Res. 1351.

Geck C 2006 Teacher Librarian 339.

Hart J 2017 "The big lesson from the world's best school system? Trust your teachers" The Guardian, 9 Aug 2017 URL https://www.theguardian.com/teacher-network/201 7/aug/09/worlds-best-school-system-trust-teacherseducation-finland [20171109].

Irianti S, Prasetyoputra P, Sasimartoyo TP 2016 Cogent Med. 31151143.

Khumaidi A "Panduan SEAQIS Research Grants 2017" Scribd URL https://de.scribd.com/document/359652454/Pandu an-SEAQIS-Research-Grants-2017 [20171108].

McGuigan KG, Joyce TM, Conro RM 1999 J. Med. Microbiol. 48785.

Nugraheni ES “Penerapan Etnoinkuiri Berbantuan Teknik Scaffolding pada Materi Energi Panas terhadap Sikap IImiah dan Kemampuan Literasi Sains" SEAQIS Research Grants 2017.

Patunru AA 2015 Asia Pasific Policy Stud. 2234.

Patel D 2017 "8 Ways Generation Z Will Differ From Millennials In The Workplace" Forbes, 21 Sep 2017 URL https://www.forbes.com/sites/deeppatel/2017/09/21/8ways-generation-z-will-differ-from-millennials-in-theworkplace [20171109].

Rotherham AJ, Willingham DT 2010 Am. Educator 3417.

Santosa P "Model 5E dan Implementasi Media Kotak Sinar Ultraviolet untuk Merespon Hambatan Belajar Siswa pada Materi Pembelajaran Fotosintesis" SEAQIS Research Grants 2017.

Savolainen R 2007 J. Inf. Sci. 33611.

Sutia C "Penerapan Pembelajaran Engineering Design Process untuk Meningkatkan Motivasi Belajar dan Kemampuan Siswa dalam Merancang Pemecahan Masalah Lingkungan" SEAQIS Research Grants 2017.

Stavy R, Eisan Y, Yaakobi D 1987 Int. J. Sci. Educ. 9105.

Tas E 2011 Energy Educ. Sci. Technol. B 3567.

Tekkaya C Özkan Ö, Sungur S 2001 Hacettepe Üniversitesi Eğitim Fakültesi Dergisi 21145. 